\title{
THE MODELING OF THE YIELDING CAPACITY OF WINTER CEREALS DUE TO SATELLITE MONITORING DATA OF AGRICULTURAL LANDS IN UKRAINE
}

\author{
Roman STUPEN ${ }^{\circledR 1}$, Zoriana RYZHOK ${ }^{1 *}{ }^{*}$, Nazar STUPEN ${ }^{\circledR 2}$, Oksana STUPEN ${ }^{\circledR 1}$ \\ ${ }^{1}$ Faculty of Land Organisation, Lviv National Agrarian University, Dublyany, Ukraine \\ ${ }^{2}$ Institute of Geodesy, Lviv Polytechnic National University, Lviv, Ukraine
}

Received 12 December 2019; accepted 12 March 2021

\begin{abstract}
The paper reveals the method of work in the geoinformation system Crop Monitoring on the basis of satellite monitoring data on the example of comparison of two neighboring land uses outside Bortkiv village council of Zolochiv district of Lviv region. One has determined the size of the areas of crops of winter cereals and deduced the dependence between the index of the vegetative index NDVI and their yield capacity on the basis of the estimation of the state of land use by the processing of space information. One has suggested to take into account the value of NDVI when calculating the yield of winter cereals using mathematical modeling. The results obtained from the satellite monitoring data are proposed to be used for the planning of winter cerels yields, determining the area of their sowing and optimizing the harvesting time.
\end{abstract}

Keywords: geoinformation systems, satellite monitoring, vegetation index, yielding capacity, Cauchy method, agricultural land use.

\section{Introduction}

The use of aerospace remote sensing facilities on Earth makes it possible to provide objective and reliable information on the ecological conditions, properties and the state of the agroecosystem, the spatial structure of natural and territorial complexes, their dynamics, including facilitates the accumulation of data for the creation and development of a system for monitoring natural resources and agrarian resources (Babych, 1998). Monitoring of agricultural lands is a prerequisite for effective regulation of the agro-industrial sector of the economy, and the use of geoinformation systems in the interests of the agroindustrial complex of Ukraine is an integral part of the process of managing agricultural land use. The application of satellite monitoring data is an extremely promising area that allows you predicting the yielding capacity, gross crop yields on the example of a certain agricultural enterprise.

Babych (1998), Zatserkovnyi et al. (2011), Kohan (2011), Lialko et al. (2006), Stupen et al. (2018) and others investigated monitoring of agricultural lands, the application of remote sensing data of the Earth in predicting crop yielding capacity in their scientific works. Scientists have justified the use of the Normalized Difference Vegetation Index (NDVI) as one of the most common and reliable index, which fully characterizes the density of vegetation and allows evaluating the germination of crops, determine the productivity of sowing and lands. After all, its size is influenced by the type of vegetation, the closeness of the plants, and the condition, exposure, and tilt angle of the surface. We also apply the values of the corresponding vegetation index to predict winter grain yielding capacity based on Earth Observing System geoinformation data using mathematical modeling as based on typical land use.

\section{Materials and methods}

To build a model for predicting the yielding capacity of crops according to satellite monitoring, we present a system of linear equations, which has the following form:

$$
\left\{\begin{array}{ccc}
N_{11} \tau_{1}+N_{12} \tau_{2}+N_{1 k} \tau_{k}+L_{1}= & 0 \\
N_{21} \tau_{1}+N_{22} \tau_{2}+N_{2 k} \tau_{k}+L_{2}= & 0 \\
\cdots & \cdots & \cdots \\
\cdots & \cdots \\
N_{k 1} \tau_{1}+N_{k 2} \tau_{2}+N_{k k} \tau_{k}+L_{k}= & 0
\end{array} .\right.
$$

There are diverse ways to solve a system of linear equations. We suggest using the Cauchy method. According to it, the system of equations can be expressed in a matrix way:

${ }^{*}$ Corresponding author. E-mail: zoryana.rizhock@gmail.com 


$$
\left[\begin{array}{cccc}
N_{11} & N_{12} & \ldots & N_{1 k} \\
N_{21} & N_{22} & \ldots & N_{2 k} \\
\ldots & \ldots & \ldots & \ldots \\
N_{k 1} & N_{k 2} & \ldots & N_{k k}
\end{array}\right]\left[\begin{array}{c}
\tau_{1} \\
\tau_{2} \\
\ldots \\
\tau_{k}
\end{array}\right]+\left[\begin{array}{c}
L_{1} \\
L_{2} \\
\ldots \\
L_{k}
\end{array}\right]=0 .
$$

To determine the unknown quantities, we calculate the determinants of matrices:

$$
\begin{aligned}
& {\left[\begin{array}{cccc}
N_{11} & N_{12} & \ldots & N_{1 k} \\
N_{21} & N_{22} & \ldots & N_{2 k} \\
\ldots & \ldots & \ldots & \ldots \\
N_{1 k} & N_{k 2} & \ldots & N_{k k}
\end{array}\right]=\mathrm{D}\left[\begin{array}{cccc}
L_{1} & N_{12} & \ldots & N_{1 k} \\
L_{2} & N_{22} & \ldots & N_{2 k} \\
\ldots & \ldots & \ldots & \ldots \\
L_{k} & N_{k 2} & \ldots & N_{k k}
\end{array}\right]=D \tau_{1}} \\
& {\left[\begin{array}{ccccc}
N_{11} & L_{1} & N_{12} & \ldots & N_{1 k} \\
N_{21} & L_{2} & N_{22} & \ldots & N_{2 k} \\
\ldots & \ldots & \ldots & \ldots & \ldots \\
N_{k 1} & L_{k} & N_{k 2} & \ldots & N_{k k}
\end{array}\right]=D \tau_{2}, \ldots} \\
& {\left[\begin{array}{ccccc}
N_{11} & N_{12} & N_{1, k-1} & \ldots & L_{1} \\
N_{21} & N_{22} & N_{2, k-1} & \ldots & L_{2} \\
\ldots & \ldots & \ldots & \ldots & \ldots \\
N_{k 1} & N_{k 2} & N_{k, k-1} & \ldots & L_{k}
\end{array}\right]=D \tau_{k} .}
\end{aligned}
$$

In the determinants $D \tau_{1}, D \tau_{2}, \ldots, D \tau_{k}$ the column of coefficients of the corresponding unknown quantity is replaced by the column of transformed free terms from the system of normal equations. Then we look for unknowns by the formulas (Voitenko, 2005):

$$
\tau_{1}=\frac{D \tau_{1}}{D}, \tau_{2}=\frac{D \tau_{2}}{D}, \ldots, \tau_{k}=\frac{D \tau_{k}}{D} .
$$

\section{Results and discussions}

Objective information on the state of major crops during growth and development is essential to optimally manage their productivity, provide landowners and land users with data on the prediction. Space monitoring data has become widespread in many countries around the world, and the remote sensing of agricultural lands is constantly expanding with the advent of new satellites or sensors (Kohan, 2011).

Nowadays one has developed a lot of space-based image processing algorithms, as well as set up satellite monitoring systems for agricultural land monitoring at the global level, which are represented on the web sites of International Production Assessment Division of the United States Department of Agriculture (United States Department of Agriculture..., 2019) and MARS project of Joint Research Center of the European Commission (An official website of the European Union, 2019).

Among a large number of modern multi-purpose geoinformation systems, we use Crop Monitoring data from Earth Observing System (2019), which allows us to work with space images and they have undergone the initial processing procedure. Considering it, we can continue to work on mapping and modeling the value of cereal yields on the example of the object of study itself.

The object of the study is land use, located on the territory of Bortkiv village council of Zolochiv district, Lviv region (outside the settlement), covering an area of 91.04 hectares for agricultural commodity production. The location of the study object according to the Sentinel-2 artificial satellite is shown in Figure 1.

One has determined the size of the areas of crops of winter cereals and deduced the dependence between the index of the vegetative index NDVI and their yielding capacity on the basis of the estimation of the state of land use by the processing of spatial information. The use of remote sensing data in the agrarian sector of the economy for the implementation of agrarian monitoring makes it possible to create an information base for predicting the state, development of the crop production sector, including for the determination of the acreage, the state of crops, quantitative and qualitative changes of sowing.

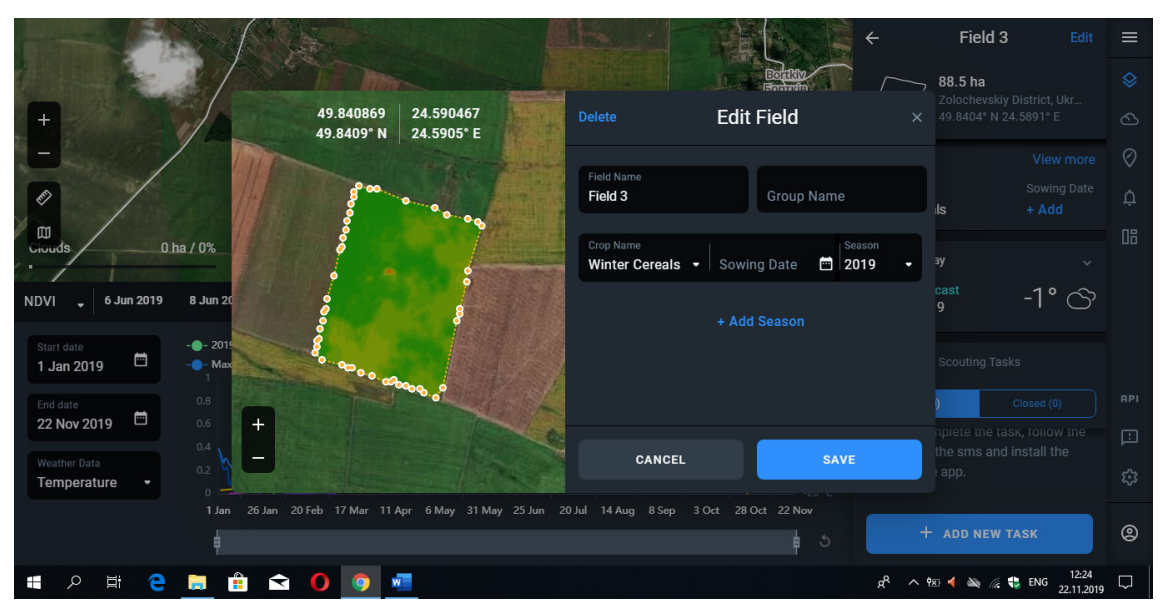

Figure 1. Display of the location of the study object in Crop Monitoring software according to the data of artificial satellite Sentinel-2 
We use NDVI indices as of May 27, June 11, June 28, and July 16, 2019 to estimate biomass change between space shots dates in the Crop Monitoring geo-information system. According to Figures 2-5 we can estimate the increase (in shades of green) and decrease (in shades of red) of biomass. Areas with a slight change in biomass are shown in yellow. Such an image makes it possible to estimate the process of harvesting winter cereals, to identify areas with depressed vegetation and to perform analytical calculations of the indicators of the economic efficiency of growing crops.

Having studied Figure 2, we consider that the average NDVI values are 0.8 in most cases between May 18 and June 17 in the years of 2016-2019 due to the research object. Thus, dense vegetation is concentrated at 82.71 hectares for the model plot of land use, moderate one 8.27 hectares, and sparse vegetation is found only at 0.06 hectares as of May 27, 2019.

Taking into account the features of the vegetation index over a long period of time, one should note that the value of NDVI correlates with the amount of photosynthetic biomass, so it is advisable to use this index to determine the period of vegetation maturation. We studied that NDVI has the highest indices as of June 11, 2019. So, compared to June 28, 2019 for the object of study the dense vegetation is on the area of 88.56 hectares, which is 5.85 hectares less than the NDVI results for dense vegetation as of June 11,2019. We can apply the results obtained according to satellite monitoring data to plan the yielding capacity of winter cereals, determine the area of their sowing and harvesting.

The difference between the NDVI results on the example of the studied land use is clearly shown in Figure 5 as of July 16, 2019. In Figure we can see as the NDVI value changes compared to its results as of June 28, 2019. According to the model farm model, we observe the value of NDVI in the range of $0.53-0.42$ in the area of 0.28 hectares, which indicates moderate vegetation, respectively, with sparse vegetation of winter cereals occupying 88.26 hectares. One can apply the results of the study to optimize the timing and quality of harvesting. It is proved that delaying the harvesting of winter cereals for 17 days leads to the loss of the crop under both favorable and unfavorable

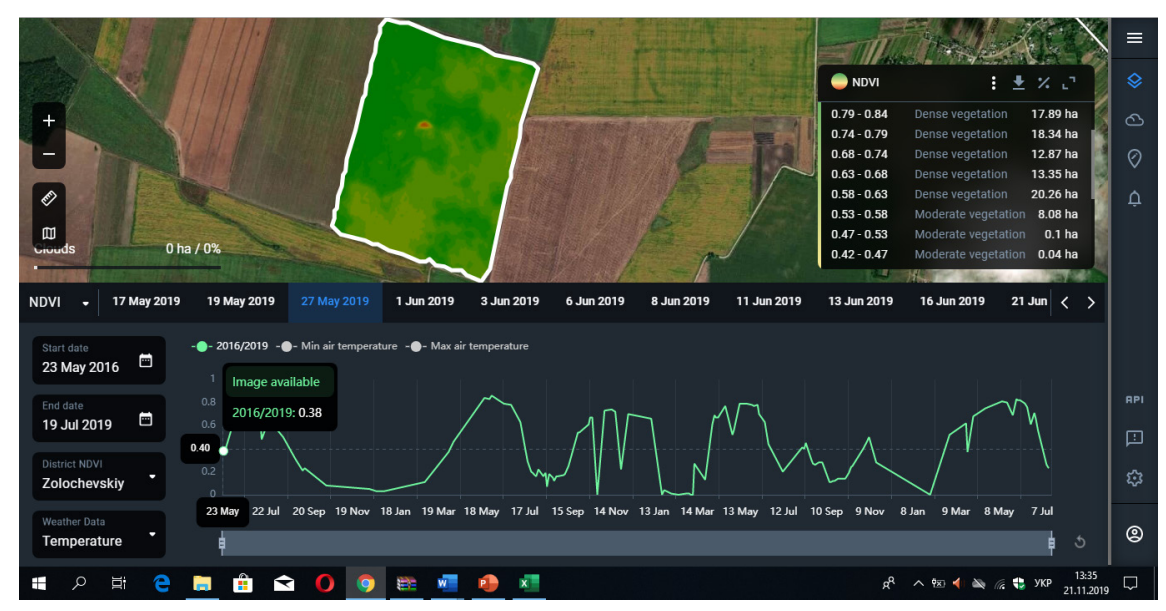

Figure 2. Image of the NDVI curve of annual flow for 2016-2019 and the state of land use by vegetation index as of May 27, 2019

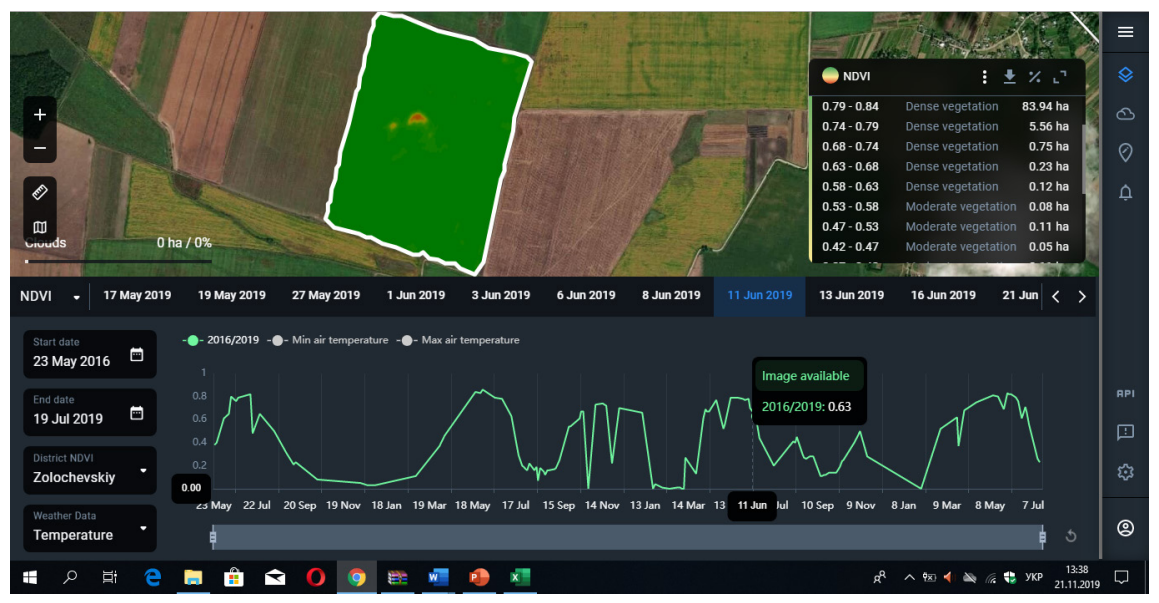

Figure 3. Image of the NDVI curve of annual flow for 2016-2019 and the state of land use according to the vegetation index as of June 11, 2019. 
harvesting conditions, which in difficult weather conditions can amount to about $80 \%$ of their crop loss.

The Normalized Difference Vegetation Index (NDVI) is one of the most common and well-founded indices. It is functionally equivalent to the simple ratio of reflected electromagnetic radiation in the red range to near-infrared radiation. By using the NDVI calculations, the normalized difference between the minimum and maximum reflection results in the reduction of various forms of multiplicative noise, namely the difference in illumination of the image, cloudiness, haze, absorption of radiation by the atmosphere present in the spectral channels of sots of different times (Dovhyi et al., 2018). We have analyzed the dynamics of NDVI in growing winter cereals for land use, located outside Bortkiv village council of Zolochiv district of Lviv region (Figure 6).

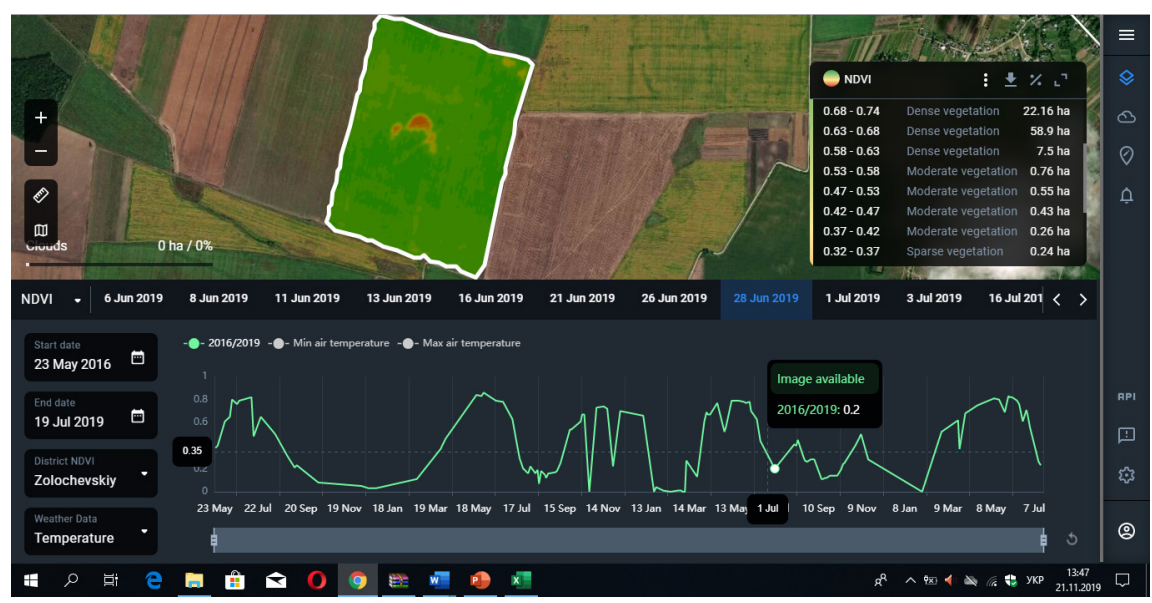

Figure 4. Image of the NDVI curve of annual flow for 2016-2019 and the state of land use according to the vegetation index as of June 28, 2019

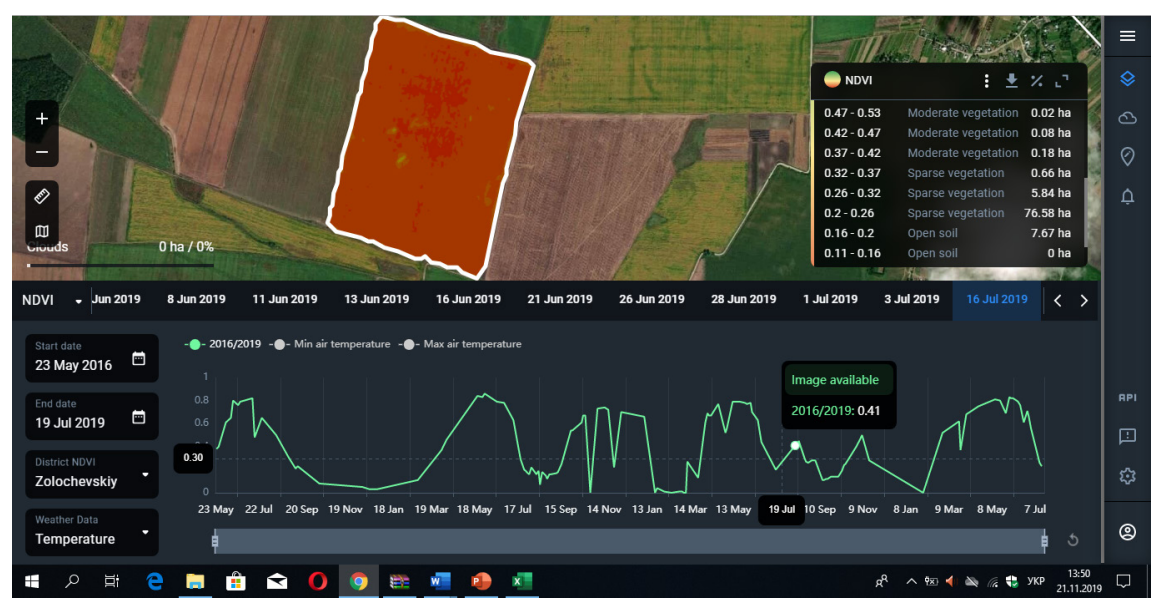

Figure 5. Image of the NDVI curve of annual flow for 2016-2019 and the state of land use according to the vegetation index as of July 16, 2019

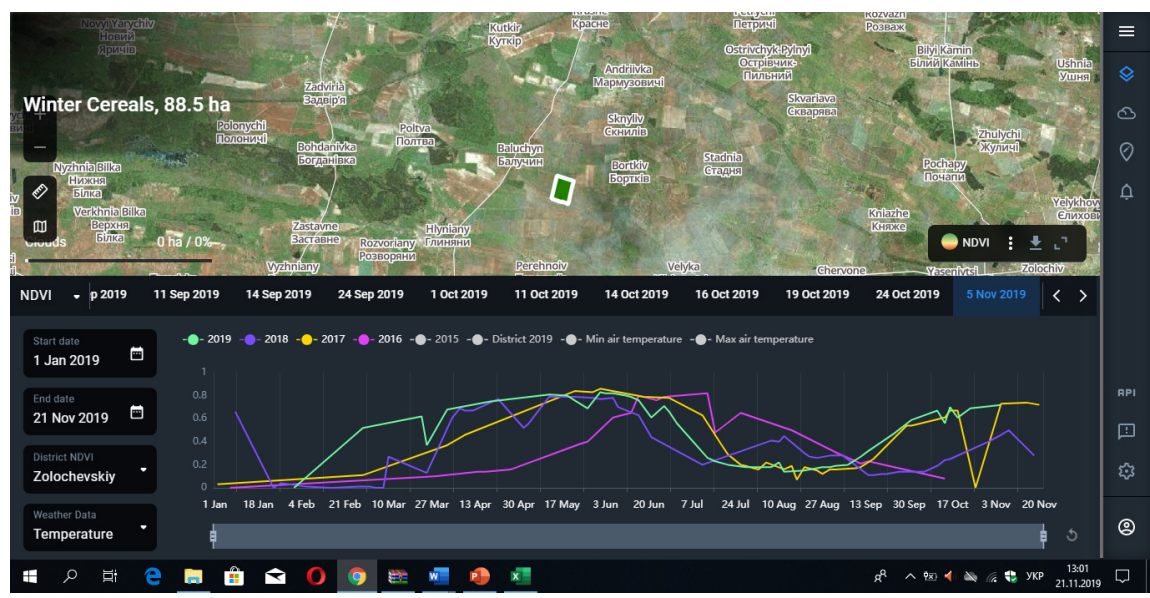

Figure 6. Dynamics of NDVI in winter cereal cultivation for model land use during 2016-2019 
Modeling is a priority tool based on a statistical analysis of local agriculture data for crop yielding capacity prediction (Stupen et al., 2019b). The information on the NDVI value obtained by Crop Monitoring is used to calculate the predicted yielding capacity level of winter cereals on the example of certain land use. Thus, we create a system of normal equations according to the initial data of Table 1. It provides information on the value of NDVI indices, which characterizes the density of the land cover, the productivity of the land and makes it possible to compare it with the yielding capacity of winter cereals according to statistics for 2016-2019 (Statistical Office in Lviv region, 2019).

Table 1. Output data for constructing a system of normal equations on the example of model land use

\begin{tabular}{|c|c|c|c|c|c|}
\hline \multirow{2}{*}{ Years } & \multicolumn{4}{|c|}{ NDVI } & Yielding \\
\cline { 2 - 6 } & May, 23 & June, 11 & June, 30 & July, 19 & $\begin{array}{c}\text { of } \\
\text { cereals, } \\
\text { c/ha }\end{array}$ \\
\hline 2019 & 0.73 & 0.8 & 0.56 & 0.20 & 51.1 \\
\hline 2018 & 0.80 & 0.68 & 0.34 & 0.28 & 45.4 \\
\hline 2017 & 0.85 & 0.84 & 0.75 & 0.29 & 55.1 \\
\hline 2016 & 0.38 & 0.64 & 0.81 & 0.55 & 50.9 \\
\hline
\end{tabular}

In the system of linear equations, the unknown quantities allow us calculating the corrections for winter cereals yields and balance their values based on NDVI data for a typical farm:

$$
\left\{\begin{array}{l}
0.73 \tau_{1}+0.80 \tau_{2}+0.56 \tau_{3}+0.20 \tau_{4}+51.1=0 \\
0.80 \tau_{1}+0.68 \tau_{2}+0.34 \tau_{3}+0.28 \tau_{4}+45.4=0 \\
0.85 \tau_{1}+0.84 \tau_{2}+0.75 \tau_{3}+0.29 \tau_{4}+55.1=0 \\
0.38 \tau_{1}+0.64 \tau_{2}+0.81 \tau_{3}+0.55 \tau_{4}+50.9=0
\end{array} .\right.
$$

We present the system of linear equations in the form of a matrix of state $A$ and $b$ :

$$
\left[\begin{array}{llll}
0.73 & 0.80 & 0.56 & 0.20 \\
0.80 & 0.68 & 0.34 & 0.28 \\
0.85 & 0.84 & 0.75 & 0.29 \\
0.38 & 0.64 & 0.81 & 0.55
\end{array}\right]=\mathrm{D}\left[\begin{array}{c}
51.1 \\
45.4 \\
55.1 \\
50.9
\end{array}\right]=\mathrm{b} .
$$

Next, we form four auxiliary matrices, replacing the columns of the state matrix A in sequence with the vector column b:

$$
\begin{aligned}
& {\left[\begin{array}{llll}
51.1 & 0.80 & 0.56 & 0.20 \\
45.4 & 0.68 & 0.34 & 0.28 \\
55.1 & 0.84 & 0.75 & 0.29 \\
50.9 & 0.64 & 0.81 & 0.55
\end{array}\right]=D \tau_{1} ;} \\
& {\left[\begin{array}{llll}
0.73 & 51.1 & 0.56 & 0.20 \\
0.80 & 45.4 & 0.34 & 0.28 \\
0.85 & 55.1 & 0.75 & 0.29 \\
0.38 & 50.9 & 0.81 & 0.55
\end{array}\right]=D \tau_{2} ;}
\end{aligned}
$$

$$
\begin{aligned}
& {\left[\begin{array}{llll}
0.73 & 0.80 & 51.1 & 0.20 \\
0.80 & 0.68 & 45.4 & 0.28 \\
0.85 & 0.84 & 55.1 & 0.29 \\
0.38 & 0.64 & 50.9 & 0.55
\end{array}\right]=D \tau_{3} ;} \\
& {\left[\begin{array}{llll}
0.73 & 0.80 & 0.56 & 51.1 \\
0.80 & 0.68 & 0.34 & 45.4 \\
0.85 & 0.84 & 0.75 & 55.1 \\
0.38 & 0.64 & 0.81 & 50.9
\end{array}\right]=D \tau_{4} .}
\end{aligned}
$$

We calculate the determinants of the state matrix A, solving it by the Cauchy method according to formula 4 :

$$
\left[\begin{array}{c}
-4.36 \\
62.34 \\
-0.72 \\
24.08
\end{array}\right]
$$

As a result of the study, the yielding capacity of winter cereals for our land use will be $62.34 \mathrm{c} / \mathrm{ha}$, which is lower than the yielding capacity of $75.85 \mathrm{c} / \mathrm{ha}$ in EU countries and depends not only on soil quality but also on economic factors of agricultural production (Stupen et al., 2019a).

The major disadvantage of creating a mathematical model for predicting crop yielding capacity is the necessity to set numerous specific parameters for each crop, such as soil characteristics, tillage methods, agrometeorological data, sowing dates (Stupen et al., 2020). One often uses the data obtained from remote sensing to build models that describe the dependence of crop yielding capacity on the number of introduced nutrients, soil conditions, the impact of environmental factors (Dovhyi, 2013). These methods are mostly uncomplicated, and their implementation does not require a significant number of parameters. However, one should take into consideration that the processes describing the yielding capacity of key crops are usually non-stationary, and one has to study yielding capacity indicators for a large number of farms in a particular soil and climatic zone (Bidyuk et al., 2017).

In order to compare the obtained results, our proposed method of mathematical modeling for predicting winter grain yielding capacity is considered on the example of the neighboring area for the study of land use, located in Bortkiv village council of Zolochiv district of Lviv region (outside the settlement), with an area of 69.7 hectares conducting commodity agricultural production (Figure 7).

Mathematical methods for predicting yielding capacity based on estimates of physical environmental factors are based on the assumption of the existence of a simple relationship between environmental characteristics and yielding capacity. Taking into account the determining role of the state of formation of plant biomass in certain phases of their development, one has applied a quantitative indicator of the vegetation index NDVI to model their yielding capacity. 


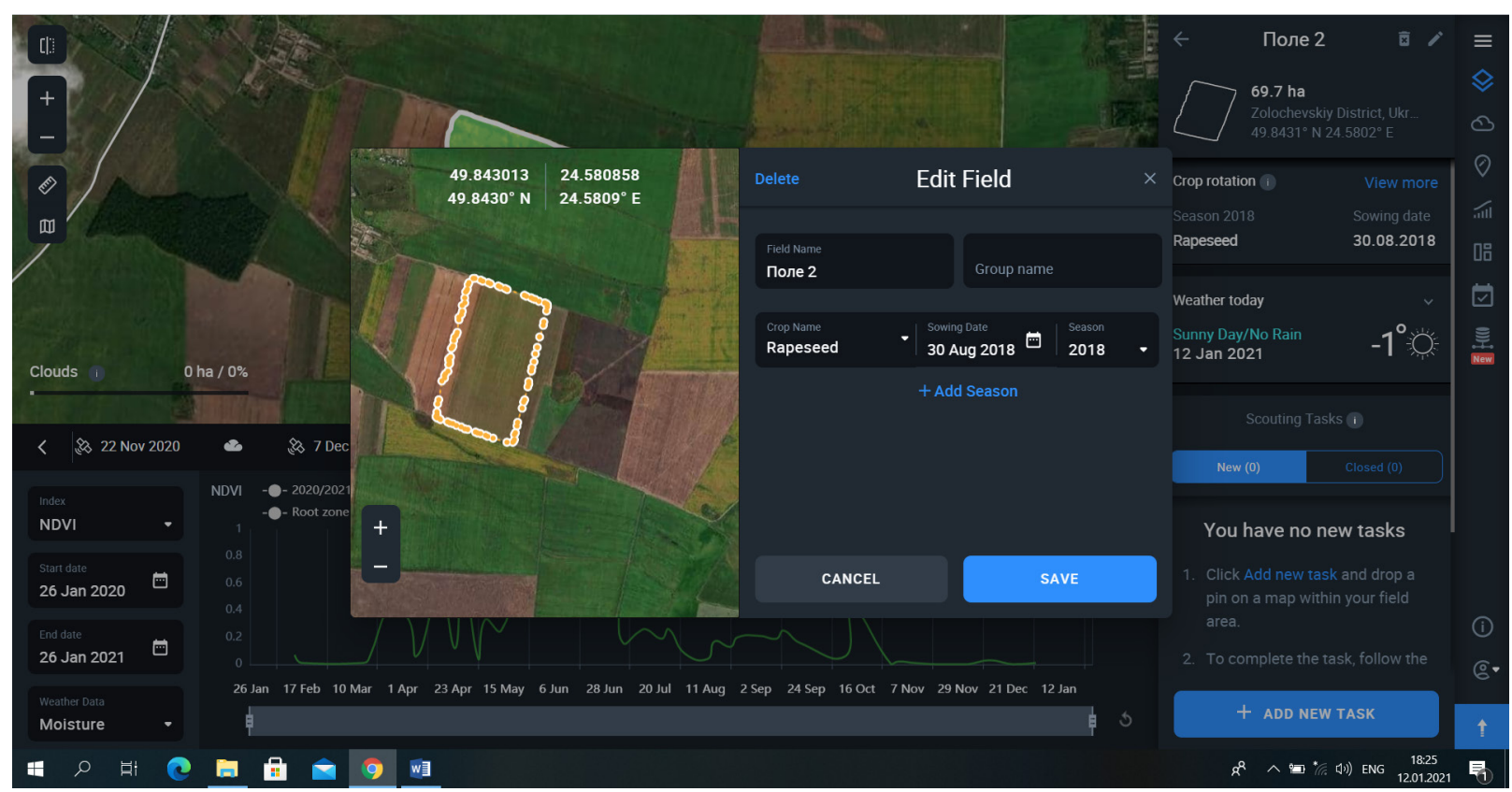

Figure 7. The reflection of the location of a neighboring area for land use object in Crop Monitoring software based on the Sentinel-2 artificial satellite

The differences between the values of the vegetation index NDVI in the territory of the neighboring area for research object of model land use as of May 27, June 11, June 28 and July 16, 2019 in the geographic information system Crop Monitoring are shown in Figures 8 and 9. From May 27 to June 11, 2019, we have observed that the value of the vegetation index NDVI is 0.3 and 0.85 , respectively, in the problem area of the field. On the neighboring area for land use study, according to the artificial satellite Sentinel-2 data in the geographic information system Crop Monitoring based on the application of the time series analysis tool for
May 27 2019, winter crops are mostly in good condition, but there is a separate area of land use, characterized by a critical condition. This is due to the uneven development of the spring vegetation of winter cereals. As of June 11, 2019, with the beginning of the milky ripe phase, the condition of sowing crops increases to a good value at the level of vegetation index NDVI $0.85-0.90$ on an area of 58 hectares with dense vegetation and reflects the highest results of winter grain vegetation (Figure 8).

Considering the period of June 28 and July 16, compared with the data of the vegetation index NDVI on June

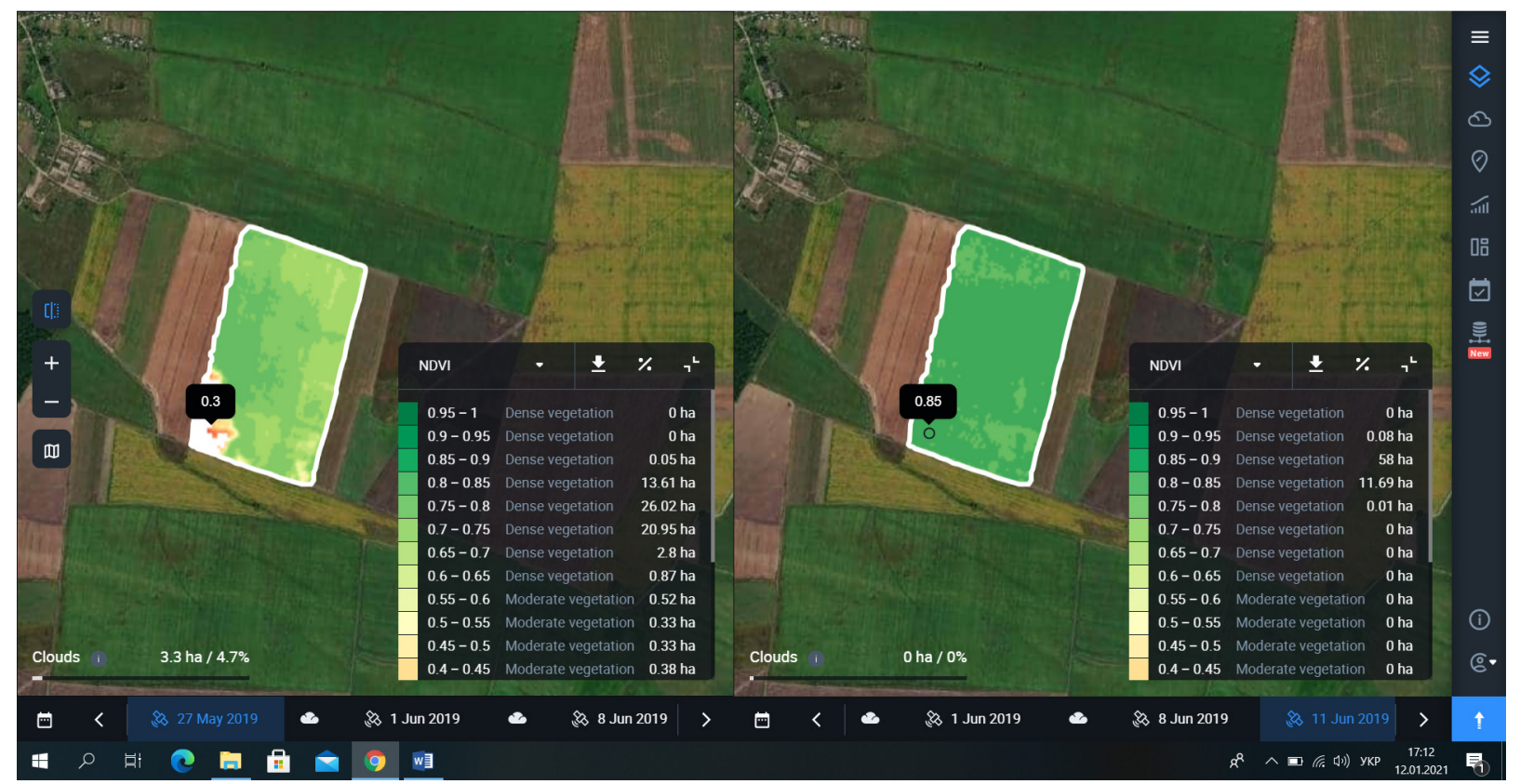

Figure 8. Comparison of the state of the neighboring area for research object of land use on the vegetation index NDVI on May 27 and June 11, 2019 
11,2019 , the state of winter grain crops significantly deteriorates to satisfactory with moderate vegetation, especially in the southern part of the neighbouring area for model land use object (Figure 9). According to the application of the comparison tool for the time series of the satellite image in Figures 8-9 in the Crop Monitoring geographic information system, one can conclude that large NDVI values in mid-June indicate a high level of early grain yielding capacity. Having analysed this fact, it is worth predicting the gross grain yielding capacity in mid-summer.

Generally, the main advantage of NDVI is simplicity of its obtaining: the calculation of the index does not require additional data and techniques, except for the space survey itself and knowledge of its parameters. The dynamics of the seasonal change of NDVI makes it possible to assess the condition of plants in diverse development phases. Considering remote sensing, the fundamentals for determining the state of vegetation, particularly crop sowing, are methods of solar radiation analysis reflected by vegetation in different ranges of the spectrum of electromagnetic waves. Thus, in the red region of the spectrum $(0.6-0.7 \mu \mathrm{m})$ there is the maximum absorption of solar radiation by chlorophyll, and in the infrared region (0.7$1.0 \mu \mathrm{m})$ there is the region of maximum reflection of the

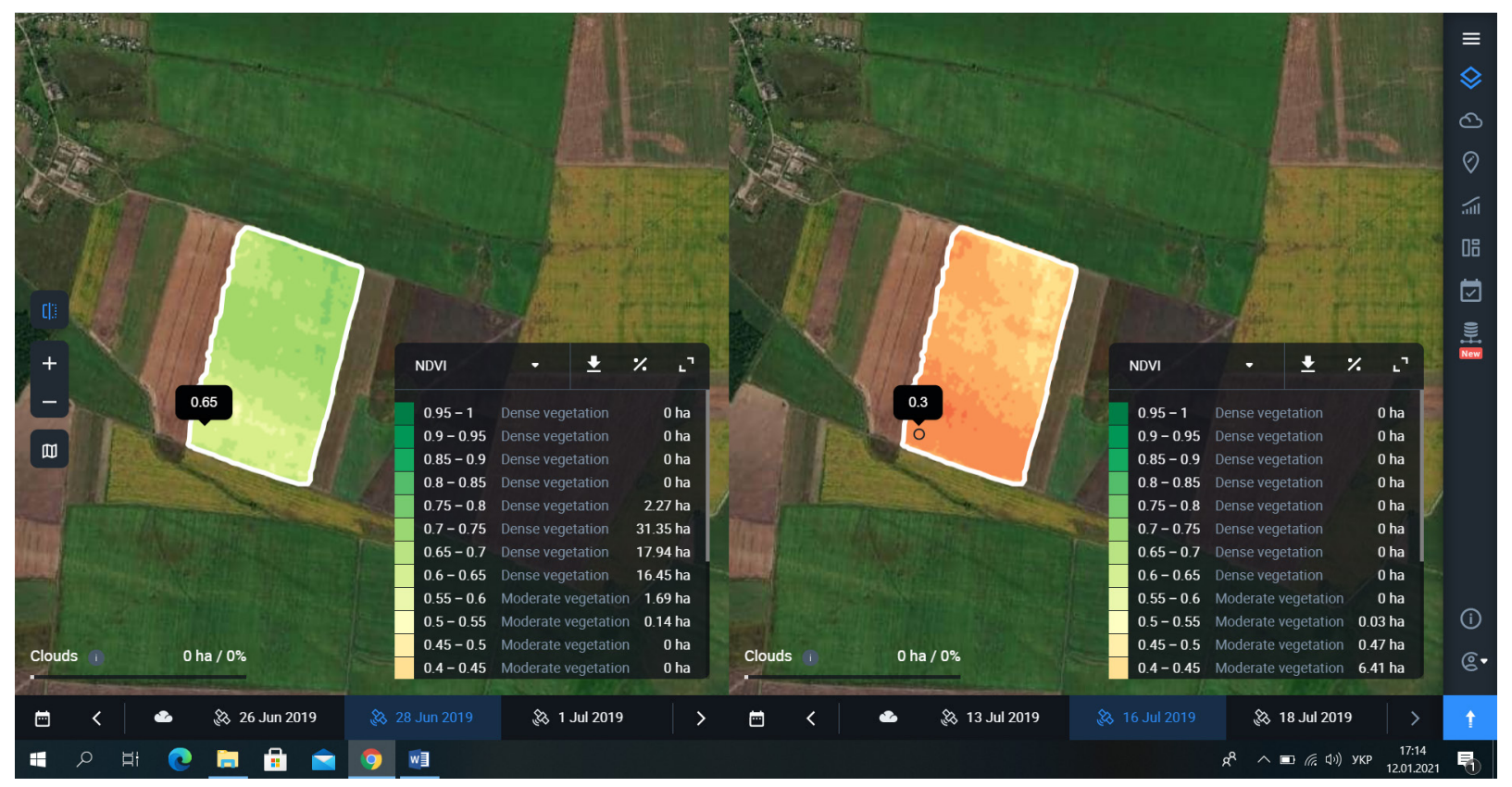

Figure 9. Comparison of the state of the neighboring area for land use object as to vegetation index NDVI on June 28 and July 16, 2019

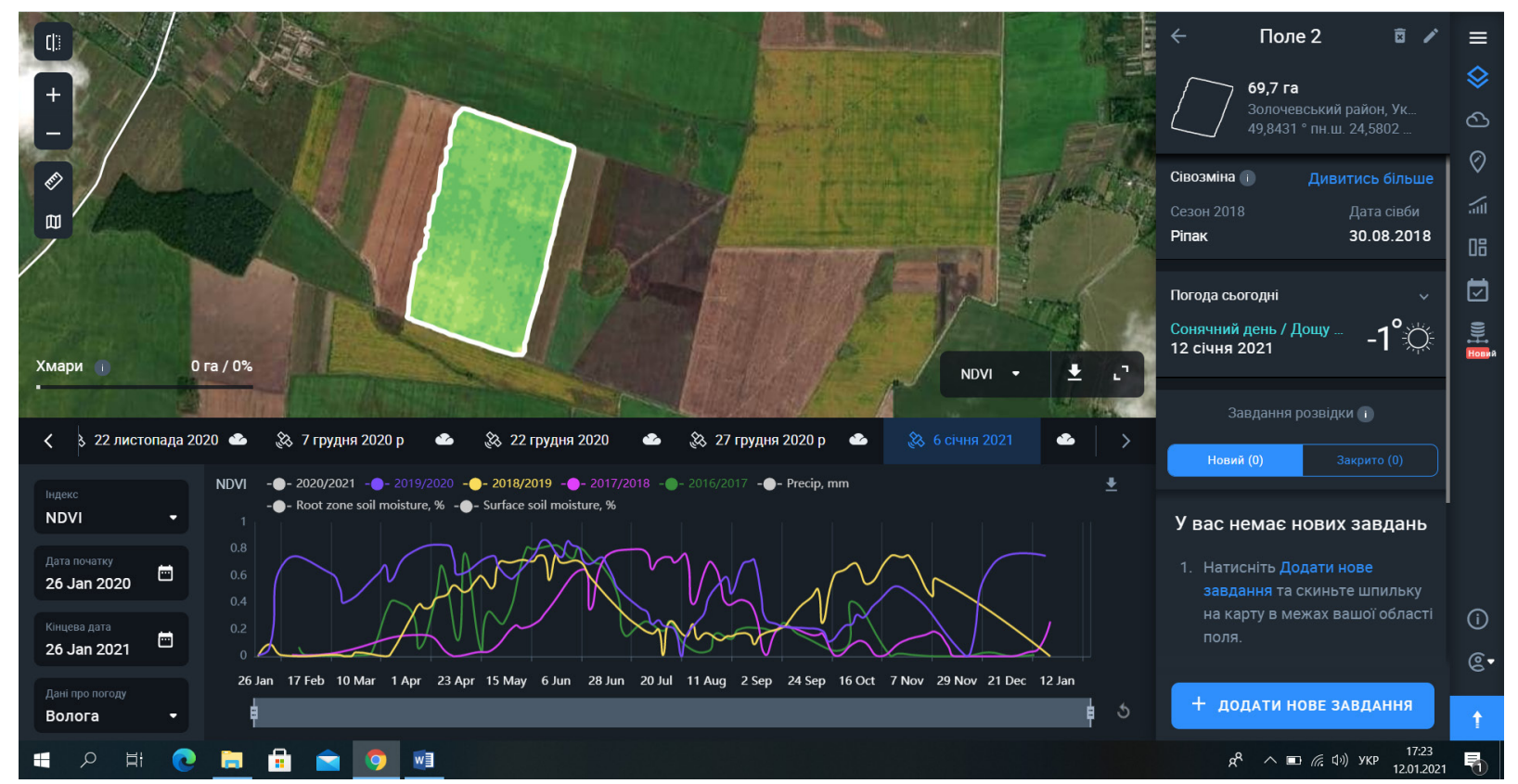

Figure 10. Dynamics of NDVI when comparing the cultivation of winter cereals in the neighboring area for land use study during 2016-2019 
leaf cell structures. High photosynthetic activity, usually associated with dense vegetation, leads to less reflection in the red region of the spectrum and more in the infrared one (Tarariko et al., 2019). Figure 10 demonstrates the dynamics of the vegetation index NDVI when comparing the cultivation of winter cereals in the neighboring area for land study of land use from 2016 to 2019 in the geographic information system Crop Monitoring. Observing Figure 10 , we can state that the maximum value of the vegetation index NDVI is different during the study period.

One has applied the determined vegetation indices of NDVI for 2016-2019 on the basis of a series of space surveys in the geoinformation system Crop Monitoring (Figure 10) so as to build a mathematical model on the example of another neighboring area for land use object located outside Bortkiv village council of Zolochiv district of Lviv region (Table 2). In addition, one has taken into account the data of statistics on the productivity of winter grain growing in the research area (Statistical Office in Lviv region, 2019). Studying Table 2, we have detected that the intensity of changes in the vegetation index NDVI during the cultivation of winter cereals for the second object of study. During the growing season, there are two maxima: the first is the phase of plants in the tube (May 23), the second one - the beginning of rapid leaf surface reduction due to drying lower tiers of a leaf (June 11), except 2017, when observing the respective periods on June 11 and 30 in the amount of 0.65 and 0.80 respectively.

Table 2. Initial data for the construction of a system of normal equations on the example of the neighboring area for the model object for the study of land use

\begin{tabular}{|c|c|c|c|c|c|}
\hline \multirow{2}{*}{ Years } & \multicolumn{4}{|c|}{ NDVI } & Winter \\
\cline { 2 - 5 } & May 23 & June 11 & June 30 & July 19 & $\begin{array}{c}\text { yielding } \\
\text { capacity, } \\
\text { c/ha }\end{array}$ \\
\hline 2019 & 0.68 & 0.86 & 0.59 & 0.27 & 51.1 \\
\hline 2018 & 0.71 & 0.71 & 0.31 & 0.20 & 45.4 \\
\hline 2017 & 0.26 & 0.65 & 0.80 & 0.72 & 55.1 \\
\hline 2016 & 0.81 & 0.73 & 0.46 & 0.19 & 50.9 \\
\hline
\end{tabular}

Modeling of crop yielding capacity based on space survey data in the Crop Monitoring geographic information system has been carried out based on data from the vegetation index NDVI, which reflects the state of sowing of the certain crop on the example of individual land use. The problem of calculating the prediction values of winter wheat yielding capacity in the neighboring area for the study of land use will allow making conclusions about the extent of difference of winter crop yielding capacity using the same method by building a mathematical model in the form of a system of linear equations, calculated matrix (formulas 1-4) according to Table 2:

$$
\begin{aligned}
& \left\{\begin{array}{l}
0.68 \tau_{1}+0.86 \tau_{2}+0.59 \tau_{3}+0.27 \tau_{4}+51.1=0 \\
0.71 \tau_{1}+0.71 \tau_{2}+0.31 \tau_{3}+0.20 \tau_{4}+45.4=0 \\
0.26 \tau_{1}+0.65 \tau_{2}+0.80 \tau_{3}+0.72 \tau_{4}+55.1=0 \\
0.81 \tau_{1}+0.73 \tau_{2}+0.46 \tau_{3}+0.19 \tau_{4}+50.9=0
\end{array}\right. \\
& {\left[\begin{array}{llll}
068 & 0.86 & 0.59 & 0.27 \\
0.71 & 0.71 & 0.31 & 0.20 \\
0.26 & 0.65 & 0.8 & 0.72 \\
0.81 & 0.73 & 0.46 & 0.19
\end{array}\right]=\mathrm{D}\left[\begin{array}{l}
51.1 \\
45.4 \\
55.1 \\
50.9
\end{array}\right]=\mathrm{b} ;}
\end{aligned}
$$$$
\left[\begin{array}{llll}
51.1 & 0.86 & 0.59 & 0.27 \\
45.4 & 0.71 & 0.31 & 0.20 \\
55.1 & 0.65 & 0.80 & 0.72 \\
50.9 & 0.73 & 0.46 & 0.19
\end{array}\right]=D \tau_{1} \text {; }
$$$$
\left[\begin{array}{llll}
0.68 & 51.1 & 0.59 & 0.27 \\
0.71 & 45.4 & 0.31 & 0.20 \\
0.26 & 55.1 & 0.80 & 0.72 \\
0.81 & 50.9 & 0.46 & 0.19
\end{array}\right]=D \tau_{2} ;
$$$$
\left[\begin{array}{llll}
0.68 & 0.86 & 51.1 & 0.27 \\
0.71 & 0.71 & 45.4 & 0.20 \\
0.26 & 0.65 & 55.1 & 0.72 \\
0.81 & 0.73 & 50.9 & 0.19
\end{array}\right]=D \tau_{3} \text {; }
$$$$
\left[\begin{array}{llll}
0.68 & 0.86 & 0.59 & 51.1 \\
0.71 & 0.71 & 0.31 & 45.4 \\
0.26 & 0.65 & 0.80 & 55.1 \\
0.81 & 0.73 & 0.46 & 50.9
\end{array}\right]=D \tau_{4} \text {. }
$$

As in the above-done calculations, the system of linear equations for the second land use has been calculated in two stages, where during the first one the values of the unknown $D \tau_{-}(n)$ have been determined, and the second the matrix of the state of $b$ :

$$
\left[\begin{array}{c}
41.83 \\
4.60 \\
11.16 \\
44.87
\end{array}\right]
$$

Comparing the productivity of winter crop growing on the neighboring territory of land use object, with an area of 69.7 hectares, located on the territory of Bortkiv village council of Zolochiv district of Lviv region (outside the settlement), the yielding capacity will be 44.87 centners per hectare. The obtained results are $28 \%$ lower than the predicted value of winter crop yielding capacity for land use, with an area of $91.04 \mathrm{ha}$, in the amount of $62.34 \mathrm{c} / \mathrm{ha}$, which allows us to conclude about the difference in the productivity of the field.

The results of the carried out modeling by initial value problem on the example of two neighboring land uses 
according to the vegetation index NDVI in the geographic information system Crop Monitoring have shown that they should be used to predict the productivity of crops at the local level, taking into account specific growing conditions (growth and development phases) in certain soil and climatic conditions, the use of agricultural technologies, the impact of adverse environmental factors.

\section{Conclusions}

The analysis of space images in the Crop Monitoring geoinformation system during different vegetation periods of winter cereal makes it possible to get a real idea of the condition of the studied land mass. Considering the results of the study, regarding the need for fertilizer application, we have sown the problem areas and predicted their yielding capacity according to the results of the NDVI index using mathematical modeling. The methodological approaches to winter cereals yield modeling represent the true state of crops by crop density during the growing season, taking into account NDVI index data and terrestrial observations.

\section{References}

An official website of the European Union. (2019). Monitoring Agricultural ResourceS (MARS).

https://ec.europa.eu/jrc/en/mars

Babych, S. (1998). Methodical aspects of analytical processing of information in aerospace monitoring of sowing. System research and modeling in agriculture. Nyva.

Bidyuk, P., Terentiev, O., Prosyankina-Zharova, T., \& Efendiev, V. (2017). Prediction modeling of nonlinear non-stationary processes in crop production using tools of SAS Enterprise Miner. Scientific news of National Technical University of Ukraine "Igor Sikorsky Kyiv Polytechnic Institute": International Scientific and Technical Journal, 1(111), 24-36. https://doi.org/10.20535/1810-0546.2017.1.87423

Dovhyi, S. (2013). Environmental monitoring using NOAA satellite survey. National Aerospace University M.E., Zhukovsky "Kharkiv Aviation Institute".

Dovhyi, S., Krasovskyi, H., Radchuk, V., \& Trofymchuk, O. (2018). Geomodels in tasks of ecological and economic land estimations. Yuston.
Earth Observing System. (2019). Crop Monitoring. https://eos.com/products/crop-monitoring/

Kohan, S. (2011). Investigation of the dynamics of vegetation indices for the estimation of the state of crops based on IRS1D LISS-III data. Bulletin of Geodesy and Cartography, 4, 20-24.

Lialko, V., Sakhatskyi, O., \& Zholobak, H. (2006). Features of prediction of gcereals yields according to multispectral data. In Multispectral methods of remote sensing of the earth in environmental problems (pp. 276-191). Scientific Thought.

Statistical Office in Lviv region. (2019). Agriculture, forestry and fisheries. http://database.ukrcensus.gov.ua/statbank_lviv/ Database/04SILGOSP/databasetree_uk.asp

Stupen, M., Stupen, N., Ryzhok, Z., \& Stupen, O. (2020). Application of satellite monitoring data for winter cereals growing in the Lviv region. Geomatics and Environmental Engineering, 14(4), 69-80. https://doi.org/10.7494/geom.2020.14.4.69

Stupen, N., Bohira, M., Stupen, O., \& Ryzhok Z. (2019a). Prospects of the application of European practice on efficient agricultural lands use in Ukraine. Scientific Papers Series "Management, Economic Engineering in Agriculture and Rural Development”, 19(3), 563-569. https://doi.org/10.31734/agrarecon2019.03.090

Stupen, N., Stupen, M., \& Stupen, O. (2018). Electronic agricultural maps formation on the basis of GIS and earth remote sensing. Scientific Papers Series "Management, Economic Engineering in Agriculture and Rural Development", 18(4), 347-353.

Stupen, R., Stupen, M., Ryzhok, Z., \& Stuppen, O. (2019b). Modeling of the effective functioning of the agricultural lands market in Ukraine. Geodesy and Cartography, 45(2), 96-101. https://doi.org/10.3846/gac.2019.7438

Tarariko, O., Sirotenko, O., Ilienko, T., \& Kuchma, T. (2019). Agro-environmental satellite monitoring. Agrarian Science.

United States Department of Agriculture. Foreign Agricultural Service. (2019). International Production Assessment Division. https://ipad.fas.usda.gov

Voitenko, A. (2005). Mathematical processing of geodetic measurements. Least-squares method: teaching manual. Kyiv National University of Construction and Architecture.

Zatserkovnyi, V., Kryvoborets, S., \& Serhienko, V. (2011). The use of GIS and remote sensing for agricultural land monitoring. Chernihiv Scientific Journal of Chernihiv State Institute of Economics and Management: Engineering and Nature, 2, 40-48. 